\title{
Stock markets are not what we think they are: the key roles of cross-ownership and corporate treasury stock
}

\author{
Bertrand M. Roehner ${ }^{1}$ \\ Institute for Theoretical and High Energy Physics \\ University Paris 7
}

\begin{abstract}
We describe and document three mechanisms by which corporations can influence or even control stock prices. (i) Parent and holding companies wield control over other publicly traded companies. (ii) Through clever management of treasury stock based on buyback programs and stock issuance, stock price fluctuations can be amplified or curbed. (iii) Finally, history shows a close interdependance between the level of stock prices on the one hand and merger and acquisition activity on the other hand. This perspective in which Boards of Directors of major companies shepherd the market offers a natural interpretation of the so-called "herd behavior" observed in stock markets. The traditional view holds that by driving profit expectations, corporations have an indirect role in shaping the market. In this paper, we suggest that over the last decades they became more and more the direct moving force of stock markets.
\end{abstract}

June 27, 2004

Preliminary version, comments are welcome

Key-words: stock markets, cross-ownership, stock buybacks, corporate gouvernance, collective behavior, herd effect

\section{1: ROEHNER@LPTHE.JUSSIEU.FR}

Postal address where correspondence should be sent:

B. Roehner, LPTHE, University Paris 7, 2 place Jussieu, F-75005 Paris, France.

E-mail: roehner@lpthe.jussieu.fr

FAX: 33144277990 


\section{Cross-ownership}

As everyone knows, Bill Gates owns about $10 \%$ of the shares of Microsoft and Jeff Bezos, the founder of Amazon holds about $25 \%$ of its shares. Altria, the company formerly known as Philip Morris, owns 84\% of the shares of Kraft Foods (NYSE: KFT), the US number one food company. In 2004 Altria's chief executive officer, Louis Camilleri, was also chairman of Kraft. Metlife, a huge insurance company, owns 53\% of the Reinsurance Group of America (NYSE: RGA) who is itself a multibillion company. Renault, the French automaker, owns $45 \%$ of Nissan Motors, Japan's number two automaker after Toyoto. One may think that these cases are exceptional. In fact, they are rather the rule. Consider the case of Germany, one of the countries for which one has detailed ownership statistics. In $58 \%$ of the publicly traded companies, the largest stockholder has more than $50 \%$ of the total voting stock; in $82 \%$ of them the largest stockholder has more than $25 \%$ of the voting stock (Prigge 1998). If one remembers that a corporation $A$ is considered to have de jure control of a company $B$ if it owns at least $25 \%$ of its voting shares, one sees that our previous statement was hardly exaggerated. In the case of the corporations which make up the Dow Jones Industrial index, table 1 shows that the percentage of the shares which are not in the hands of the company, of insiders or of institutions is on average equal to $28 \%$.

What are the consequences in terms of stock price behavior? Fig. 1 shows the correlation between Renault and Nissan stock prices over the last decade. There is a clear transition from the period before takeover during which the two stocks moved almost independently from each other to a regime characterized by a cross-correlation of the order of 0.75 . When one party holds almost $50 \%$ of the shares it can control the price to some extent. Perhaps, the majority stockholder will not care to exercise that control is everyday transactions, but in case of sudden price fluctuations there is documented evidence that it will (see below). This observation is by no means in contradiction with the market efficiency tenet of economic theory. As a matter of fact, the smaller the number of major players, the quicker the market is able to respond to new information. For commodities a market where one trader has about $50 \%$ of the inventory would hardly be considered as a perfectly competitive market but rather as one with monopolistic competition. As a result, it would highly questionable to model and simulate such a market as a set of numerous agents, each of whom has only a small action on the market.

The fact that acquisitions, buyouts, takeovers and mergers are major corporate issues is attested by the warlike expressions used in corporate parlance. Expressions such as blitzkrieg tender offer ${ }^{1}$, scortched-earth policy, shark repellent, target company, porcupine provision, sleeping beauty, and many others were coined in order to describe offensive and defensive tactics; they reveal that these questions are major concerns of corporate management.

Cross-ownership and control by a majority owner would be sufficient to substantially alter the traditional view, but this is only part of the story. In the next section we analyze the effect of buyback programs.

\section{Buyback programs}

Between 1995 and 1998, IBM bought back 772 millions of its shares ${ }^{2}$, which represents $46 \%$ of its total shares oustanding (1690 million shares in 2003). Over the same period of time, the price of its stock jumped from \$15 in Januray 1995 to \$90 in December 1998. Once bought back, these shares were withdrawn from the amount of shares outstanding and kept in treasury stock (definitions of these

\footnotetext{
${ }^{1}$ In a takeover, it is a tender offer which is so compelling that it is accepted very quickly.

${ }^{2}$ WallStreetWishlist.com
} 


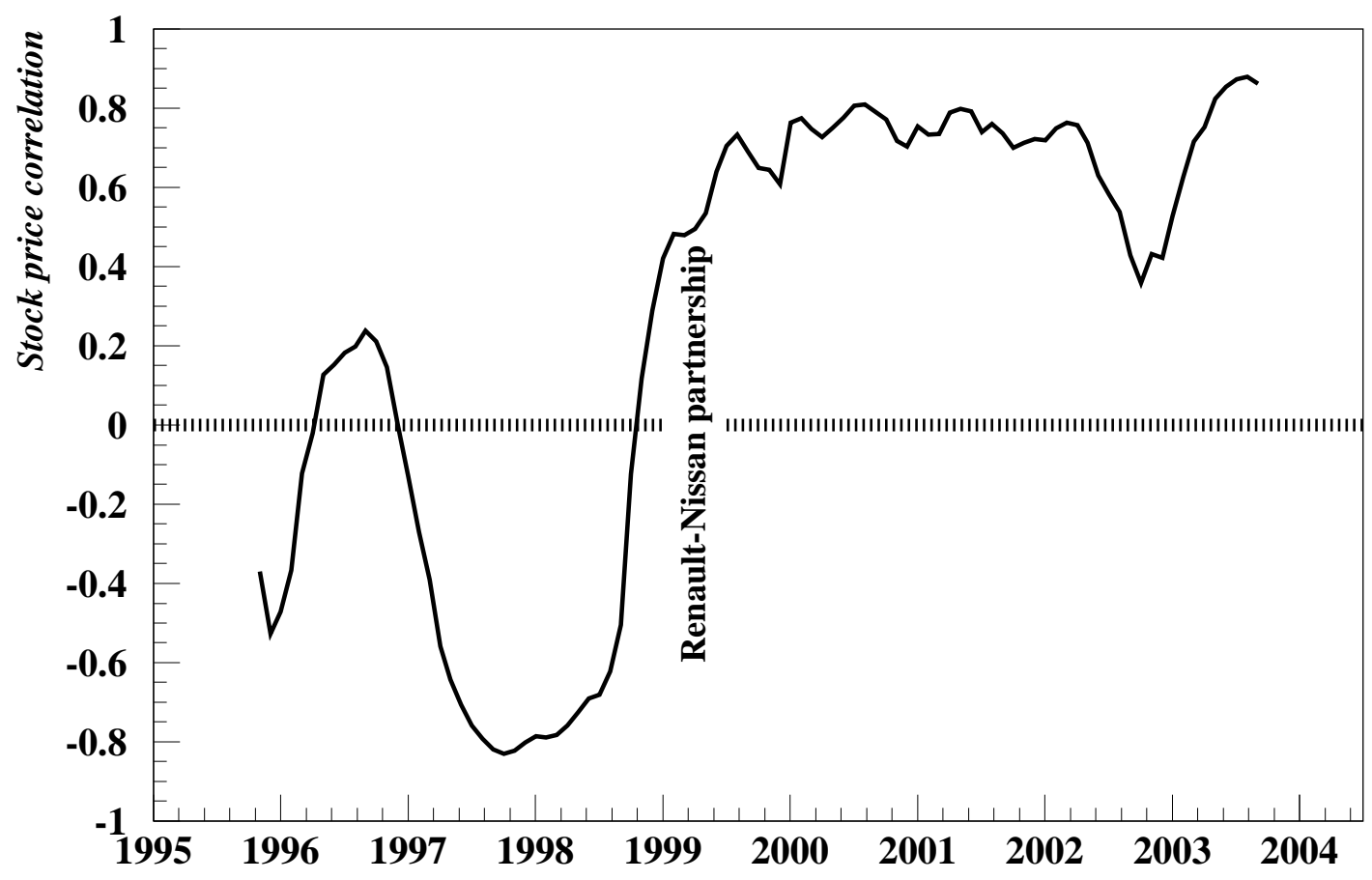

Fig.1: Correlation between Nissan and Renault stock prices. In April 1999, the French automaker took a 36.8\% stake in Nissan; in March 2002, it increased it stake to 44.4\% while at the same time Nissan acquired $15 \%$ of Renault. The figure shows that this cross-ownership brought about a marked increase in the correlation between the stock prices of the two companies. That this implication is not as obvious as could seem is illustrated by the counterexample of Renault Argentina which, although $100 \%$ owned by the parent company, shows little price correlation with Renault itself. The moving window used for computating the correlation has a width of 21 months. Assessing interaction strengths of public companies is a key issue for a better understanding of stock markets and in recent years a number of promising approaches have been tried by several teams of econophysicists among which one can mention Bonano et al (2001), Drozdz et al 2001, Kim et al (2004), Mantegna (1999), Menezes et al (2004), Plerou et al (2001), Sornette et al (2003), Stauffer et al (1999). Source: http://finance.yahoo.com/

terms are recalled in Fig. 2). It is of interest to observe that in March 2002, IBM's treasury stock held only $15 \%$ of shares outstanding. What became of the rest of the shares which were bought back will be considered in a moment.

From Alcoa to Citigroup, to Merck, to Exxon Mobil, most corporations implement similar buyback plans. For instance, between 1994 and 2003, Merck bought back 528 million shares which represents $24 \%$ of its shares outstanding ${ }^{3}$. Over the same period the price of its stock jumped from $\$ 10$ to $\$ 45$. At global market level, announced buyback plans increased from \$26 billions in 1991 to \$236 billions in 2001. This later amount represents about $2.2 \%$ of the annual trading volume on the New York Stock Exchange.

The treasury stock has become an important component in the strategy of many corporations. This is shown by its mere magnitude. From the data extracted from the $10-\mathrm{K}$ reports destined to the Securities and Exchange Commission, it can be seen (table 1) that the treasury stock represents on average $15 \%$ of the shares outstanding. The three largest percentages are Coca Cola (43\%), Merck (34\%) and

\footnotetext{
${ }^{3} 10-K$ Securities and Exchange Commission filing (March 10, 2004).
} 
Table 1 Repartition of the shares of DJI corporations

\begin{tabular}{llccccc}
\hline \hline Symbol & Corporation & $\begin{array}{c}\text { Shares } \\
\text { authorized } \\
\text { not yet issued }\end{array}$ & $\begin{array}{c}\text { Treasury } \\
\text { stock }\end{array}$ & $\begin{array}{c}\text { Shares } \\
\text { oustanding }\end{array}$ & $\begin{array}{c}\text { Non institutional } \\
\text { shares }\end{array}$ & $\begin{array}{c}\text { Price change } \\
9 / 10-9 / 17 \\
2001\end{array}$ \\
& & & & & {$[\%]$} & {$[\%]$} \\
\hline AA & Alcoa & & 6.4 & 100 & 19 & -11 \\
AIG & Am.Inter. Gr. & 91 & 5.4 & 100 & 32 & -4.3 \\
BA & Boeing & 42 & 20 & 100 & 14 & -17 \\
C & Citigroup & & 5.9 & 100 & 29 & -6.7 \\
CAT & Caterpillar & 163 & 19 & 100 & 21 & -7.1 \\
DD & Du Pont & 80 & 8.7 & 100 & 37 & -10 \\
HD & Home Depot & 75 & 4.2 & 100 & 32 & -18 \\
HON & Honeywell & 350 & 6.3 & 100 & 35 & -10 \\
IBM & IBM & 132 & 11 & 100 & 11 & -17 \\
JNJ & Johns. and Johns. & 177 & 15 & 100 & 36 & -3.2 \\
JPM & JP Morgan Ch. & 45 & 5.1 & 100 & 36 & 0.37 \\
KO & Coca Cola & 116 & 0.30 & 100 & 31 & -5.6 \\
MCD & McDonalds & 178 & 31 & 100 & 21 & -1.8 \\
MMM & 3M & & 8.4 & 100 & 24 & -6.7 \\
MRK & Merk & 143 & 34 & 100 & 30 & 1.7 \\
PFE & Pfizer & 57 & 14 & 100 & 30 & 0.0 \\
SBC & SBC Comm. & & 3.9 & 100 & 44 & 1.8 \\
UTX & United Techn. & 290 & 28 & 100 & 14 & -26 \\
XOM & Exxon Mobil & 38 & 22 & 100 & 38 & -2.6 \\
& & & & & & \\
Average & & $\mathbf{1 3 2}$ & $\mathbf{1 5}$ & $\mathbf{1 0 0}$ & $\mathbf{2 8 \%}$ & $\mathbf{- 7 . 2 \%}$ \\
\hline & & & & & &
\end{tabular}

Notes: The data refer to the situation in early 2004. The numbers of shares outstanding have been normalized to 100 . The number of shares issued is the sum of the treasury stock and of the shares outstanding. The column labelled "Non institutional shares" gives the ratio: (Shares issued not held by insiders or institutions or mutual funds) /(shares issued). The fact that this ratio refers to the shares issued rather than to the shares outstanding reflects the fact that, once issued, shares can be moved out of or back into the treasury depending on the strategy of the company. The table lists the companies for which adequate data could be found in SEC 10-K reports. Note that we did not try to make a distinction between institutions such as investment banks on one hand and mutual funds on the other hand, because there is no clearly defined borderline between them. For instance, State Street Corporation (NYSE: STT, market capitalization worth $\$ 16$ billions) is a financial holding company which is registered as an institution but through its subsidiaries it has close links with the world of mutual funds as well.

Source: SEC Filings (10-K reports), http://finance.yahoo.com/

McDonalds (31\%), while the three smallest are JP Morgan Chase (0.30\%), SBC Communications $(3.9 \%)$ and Walt Disney (4.2\%).

With the development of stock options, the treasury stock has become even more important than it used to be. When an executive exercises her options by buying 100,000 shares where do these shares come from? Usually, from the treasury stock. Naturally, to generate a profit the shares must be resold immediately at market price after having been bought at the reduced option price. The net result of the operation is that the shares have been moved from the treasury to the set of outstanding shares. 


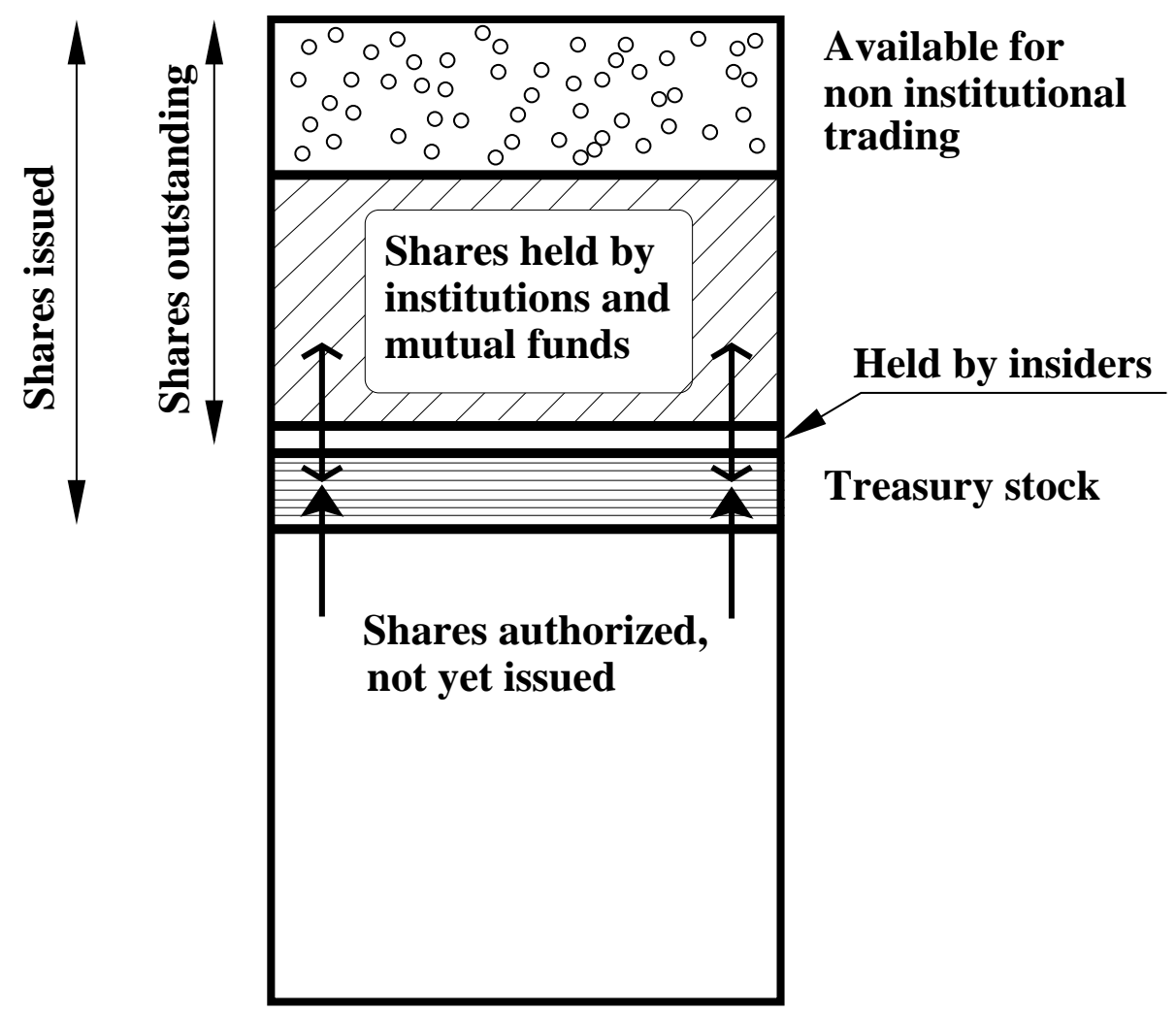

Fig.2: Schematic structure of the stock of large corporations. Sizes of the different components are drawn in conformity with the averages given in table 1 . As can be seen, the shares available for non-institutional trading represent only the tip of the iceberg. The mechanism by which shares authorized but not yet issued are transformed into regular stock (up-pointing arrows) amounts to a money-creation process. During the period 1995 to 2000, on the basis of an average NYSE capitalization of the order of $\$ 9,700$ billions, the potential of this mechanism amounted to three times the increase of the M3 stock of money in the United States. Such a potential is of particular importance in takeover operations. Source: Table 1.

Repeated many times, such operations tend to inflate the amount of oustanding shares, something stockholders see with much displeasure because it lessens the dividends to be paid for each share ${ }^{4}$. This leads the Boards of Directors to set up buyback plans 5 .

Of course, there may be other reasons as well such as for instance to support stock prices. In the repurchase of shares on the open market, SEC regulation imposes that on any single day, the purchases do not exceed $25 \%$ of the average daily trading volume. However, the SEC has the ability to loosen these restrictions in special circumstances for instance after a crash. It did so in the days following September 11, 2001 (Gabelli 2003). The following paragraph provides a test of the role of treasury stock in this connection.

Role of treasury stock in the days after 9/11 The last column of table 1 gives the price change between September 10, 2001 and September 17 when the market reopened. If we discard Boeing and United Technologies which are obvious outliers due to their links with the aerospace industry (which was especially hard hit), there is a correlation of 0.44 between sizes of treasury stock and price changes. In other words, the larger the treasury stock, the smaller was the price fall. The three

\footnotetext{
${ }^{4}$ At this point, one should mention the fact that over the last decade more and more companies gave up distributing dividends; other ways for rewarding shareholders have been introduced among which share buyback is the most important.

${ }^{5}$ This is announced in the SEC filings by sentences like the following: "IBM will repurchase shares on the open market or in private transactions" (May 7, 2004).
} 
companies with the smallest treasury (2.8\% on average), namely JP Morgan Chase, SBC Communications and Walt Disney experienced a decrease of $7.3 \%$, whereas at the other end of the spectrum, companies such as Coca Cola, Merck and MacDonalds with an average treasury of $36 \%$ experienced a price increase of $0.11 \%$. This does not necessarily mean that corporations stepped in massively to support their stock; it can also be interpreted by saying that knowing that, if necessary (that is to say in case of a substantial drop) they could do so, was certainly reassuring for institutional investors who therefore abstained from selling. The effect shown by $9 / 11$ could be confirmed by studying other crash episodes. More on this will be said in a subsequent paper.

Another important usage of treasury stock is for acquisitions. For instance, when Alcoa acquired part of Aluminio in 2002, it used 17 million shares representing 2.1\% of its shares outstanding. Similarly, back in 2001, when the American International Group bought American General Corporation in a major takeover, it used $\$ 2.3$ billions of its treasury stock. As can be seen in table 1 , in most cases the amount of shares authorized greatly exceeds the total amount of shares oustanding plus treasury shares. This gives companies a kind of money-creation power: by issuing new shares, the treasury stock can (under some conditions) be replenished and used for acquisitions and stock options operations.

\section{Merger and acquisitions}

In order for a company $A$ to purchase some or all outstanding shares of a company $B$, there are basically three procedures.

- Open market purchases at the current market price.

- Negociated private transaction. In this strategy, company $A$ will try to convince a big investor to sell a large block of stock.

- Tender offer. In this case, company $A$ offers to repurchase a fixed amount of stock at a specified price within a period which is usually of the order of one month. In order to make the offer attractive, the price is set at level above the current market price. Very often the announcement of a tender offer brings about a sudden and huge price increase.

For instance, in a recent case, after Omnicare (NYSE: OCR) announced a tender offer to purchase all of the outstanding shares of Neighborcare (NASDAQ: NCRX, market capitalization in June 2004 worth $\$ 1.4$ billion), the price of Neighborcare stock jumped from \$17 on May 20, 2004 to \$29 on May 25, 2004, a 70\% increase within 3 business days.

Incidentally, such an effect which is not only completely deterministic but also fairly predictable, does not fit well with the random walk hypothesis. Initial Public Offerings (IPO) are another example of price evolution shaped by underwriters. Indeed, the actual offering is deliberately set at a level which will create an artificial shortage and send the price upward. But that price increase will be followed by a dip when the company insiders sell their shares. Indeed, according to regulation they must wait at least 90 days (the so-called lock up period) before they can sell, which means that the price is bound to drop about 3 months after the initial offering.

Coming back to the merger and acquisition procedure, we see that whatever strategy is used, it tends to push up the price of the shares of company $B$. One may therefore expect intense merger and acquisition activity to produce an overall increase of stock price levels. The 1990s were indeed a time of high merger activity marked in addition by several multibillion mega-mergers, for instance Merk/Medco (1993), Exxon/Mobil (1998), BP/Amoco/Arco (1998-1999), Total/Elf/Fina (1998-1999), Chevron/Texaco/Caltex (2001). Over the period 1991-2000 there were on average 5,500 mergers and acquisitions annually as compared to 2,500 during the previous decade. As shown in 
Fig.3a, there was a fairly close correlation between the rise in merger and acquisition activity and the increase in stock prices (the correlation is equal to 0.95). If mergers tend to push up stock prices, in return inflated stock prices facilitate takeovers because usually a substantial fraction of the deal is paid in shares. Because of this two-way interdependence, it would be pointless to ask which was the cause and which the consequence.
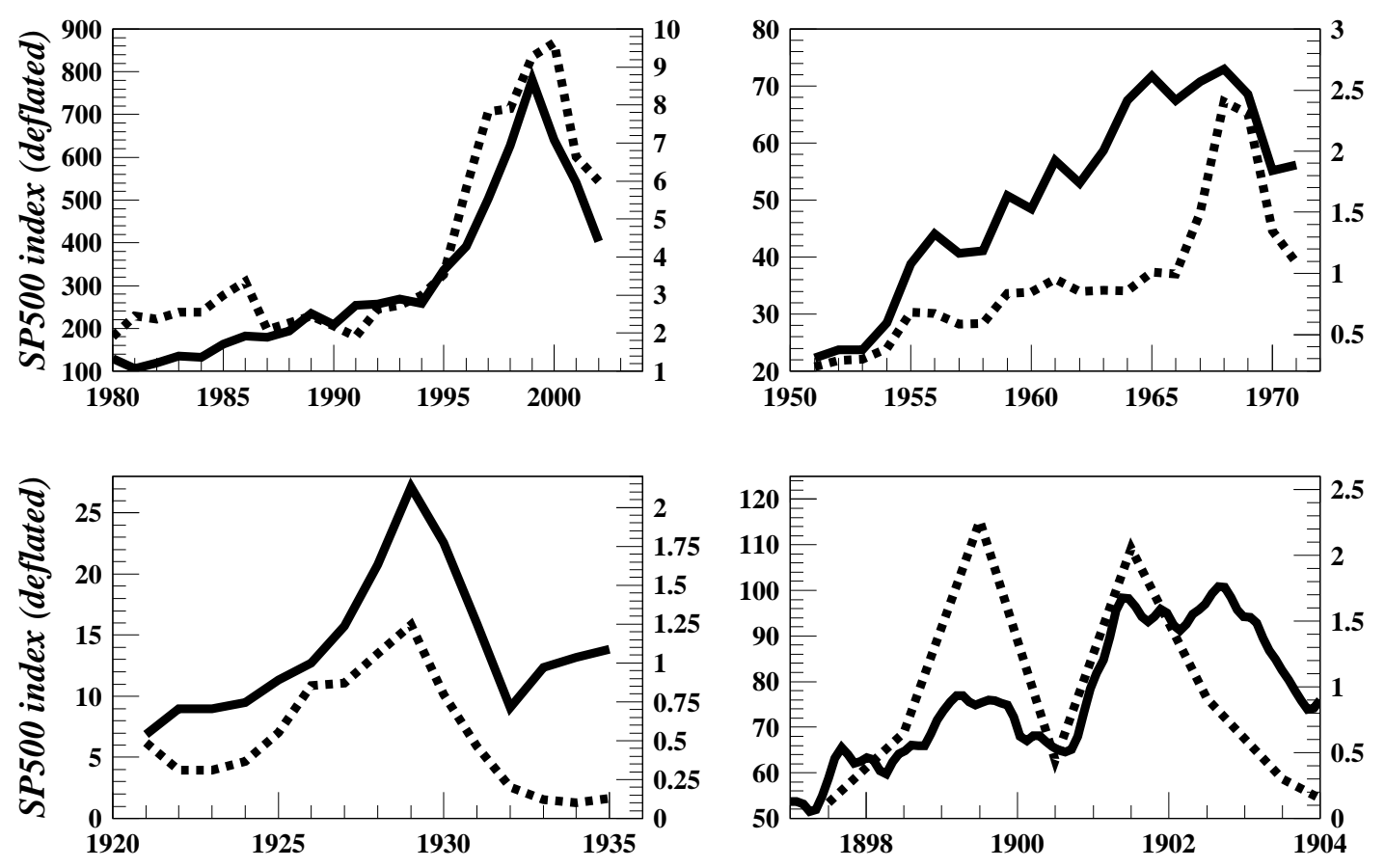

Fig.3: Relationship between merger and acquisition activity on one hand and overall level of stock prices on the other hand. Solid line: stock price level (left-hand scale); broken line: number of mergers and acquisitions in thousands (right-hand scale). Four major price peaks are considered. (a) Upper lefthand panel: price increase which started in 1980 and gathered speed in the 1990s; the regression coefficient of percentage changes is 0.27 . (b) Upper right-hand panel: the price increase started in the 1950s and culminated in 1968; the regression coefficient of percentage changes is 0.32 . (c) The lower left-hand panel shows the price peak which led to the crash of october 1929; the regression coefficient of percentage changes is 0.29. (d) Lower right-hand panel: the price peak which culminated in 1902 was substantially smaller and shorter than subsequent ones; the small number of data points does not permit to compute regression coefficients in a reliable way. Purchasing a company is an operation which boosts the demand for stocks and pushes up their price level. In return higher stock prices facilitate takeovers because a sizeable part of the deal may be paid in shares instead of cash. As a result this is a two-way interaction and it would be meaningless to wonder which of the two factors is the cause and which the consequence. Sources: Historical Statistics of the United States (1975), Farrel (1972), http://finance.yahoo.com.

Fig. 3b,c,d shows that the same scenario repeated itself during former price peaks. The price peak of 1897-1904 was much shorter than subsequent price peaks. The small number of points did not allow to compute regression estimates, but for the other three cases the regression coefficients of percentage changes are fairly close around 0.30 . On average, we get the following relationship:

$$
\frac{\Delta \text { Stock prices }}{\text { Stock prices }}=a \frac{\Delta \text { Mergers }}{\text { Mergers }}+b \quad \text { where: } a=0.29 \pm 0.14, \quad b=5.0 \pm 4
$$




\section{Conclusion}

In the face of the above evidence, why are researchers reluctant to incorporate corporations as direct players into their multiagent, multifractal models? Why do economists continue to discuss the question of whether or not there are indeed speculative peaks without taking into account the fact that buyback programs added to merger and acquisition activity force upon the market an articial dearth of stocks which invalidates value-based expectations? There is probably a historical reason to this.

For a long time, stock markets have indeed been working as fairly competitive markets. There were no stock options, fewer public companies were controlled by large corporations, merger and acquisitions had to be paid for mostly in cash. The creation of derivative markets was a major change that occurred over the last 20 years. Because of their novelty, these markets required new theoretical tools which have indeed been developed (see the vast literature on Black-Scholes Option Pricing Models). However, probably because structural novelties in stock markets were less appearant, the major changes described in this paper failed to be incorporated into standard models.

This study continues previous work (Roehner 2001, 2002, Maslov and Roehner 2004) in which we called into question some of the underlying assumptions of standard models. Once the leading role of corporations is recognized and accepted, one of the first tasks will be to identify and estimate the cross-ownership connections as we did for Renault and Nissan. Because, stock markets are multifaceted, many additional studies will be required in order to work out and formalize the present framework and to derive all its implications.

Acknowledgment I am most grateful to Professor Bruce Mizrach (Rutgers) for sharing with me his thorough knowledge of stock market mechanisms. 


\section{References}

Bonanno (G.), Lillo (F.), Mantegna (R.) 2001: Levels of complexity in financial markets. Physica A 299,16-27.

Drozdz (S.), Kwapien (J.), Grümmer, Ruf (F.), Speth (J.) 2001: Quantifying the dynamics of financial correlations. Physica A 299,144-153.

Farrel (M.L.) 1972: The Dow Jones averages 1885-1970. Dow Jones Books. Princeton.

Gabelli and Company 2003: Tender offer. The Dutch variety. (http://www.gabelli.com April 21, 2003).

Kim (K.), Yoon (S.-M.), Choi (J.S.), Takayasu (H.) 2004: Herd behaviors in financial markets. Preprint available on: http://arXiv.org/abs/cond-mat/0405172(9 May).

Mantegna (R.N.) 1999: Hierarchical structure in financial markets. The European Physical Journal B 11,193-197.

Maslov (S.), Roehner (B.M.) 2004: The conundrum of stock versus bond prices. Physica A 335,164182.

Menezes (M.A. de), Barabási (A.-L.) 2004: Separating internal and external dynamics of complex systems. Preprint available on: http://arXiv.org/abs/cond-mat/0406421 (18 June).

Plerou (V.), Gopikrishnan (P.), Rosenow (B.), Amaral (L.A.N.), Stanley (H.E.) 2001: Collective behavior of stock price movements: A random matrix theory approach. Physica 299,175-180.

Prigge (S.) 1998: A survey of German corporate governance. in Hopt (K.J.), Kanda (H.), Roe (M.J.), Wymeer (E.), Prigge (S.) eds, Claredon Press, Oxford.

Roehner (B.M.) 2001: Hidden collective factors in speculative trading. Springer-Verlag. Berlin.

Roehner (B.M.) 2002: Patterns of speculation. Cambridge University Press, Cambridge.

Sornette (D.), Gilbert (T.), Helmstetter (A.), Ageon (Y.) 2003: Endogenous versus exogenous shocks in complex networks: an empirical test. Preprint available on: http://arXiv.org/abs/cond-mat/0310135.

Stauffer (D.), Sornette (D.) 1999: Self-organized percolation model for stock market fluctuations. Physica A 271, 496-506. 